\title{
Dermoscopic Description of Fibroepithelioma of Pinkus With Negative Network
}

\author{
Yousif Yonan ${ }^{1}$, Connor Maly ${ }^{1}$, David DiCaudo ${ }^{1}$, Aaron Mangold ${ }^{1}$, Mark Pittelkow ${ }^{1}$, David Swanson ${ }^{1}$
}

1 Department of Dermatology, Mayo Clinic Arizona, Scottsdale, AZ, USA

Key words: fibroepithelioma of Pinkus, inverse network, dermoscopy, basal cell carcinoma

Citation: Yonan Y, Maly C, DiCaudo D, Mangold A, Pittelkow M, Swanson D. Dermoscopic description of fibroepithelioma of Pinkus with negative network. Dermatol Pract Concept. 2019;9(3):246-247. DOI: https://doi.org/10.5826/dpc.0903a23

Accepted: February 27, 2019; Published: July 31, 2019

Copyright: @2019 Yonan et al. This is an open-access article distributed under the terms of the Creative Commons Attribution License, which permits unrestricted use, distribution, and reproduction in any medium, provided the original author and source are credited.

Funding: None.

Competing interests: The authors have no conflicts of interest to disclose.

Authorship: All authors have contributed significantly to this publication.

Corresponding author: David L. Swanson, MD, 13400 East Shea Blvd., Scottsdale, AZ 85259. Email: Swanson.david@mayo.edu.

\section{Introduction}

Fibroepithelioma of Pinkus (FeP), a rare subtype of basal cell carcinoma, classically presents on the trunk as a pink, light brown, or skin-colored papule or plaque. Dermoscopy is a tool that can be utilized by dermatologists to correctly diagnose FeP. The dermoscopic features of FeP include polymorphous vessels, crystalline structures, milia-like cysts, ulceration, gray-brown areas, and gray-blue dots [1]. We present a case of $\mathrm{FeP}$ with negative network.

\section{Case Presentation}

A 74-year-old man presented to our clinic with a 6-month history of a slowly growing, scaly, and irritated lesion on the left flank. On examination he was found to have a roughly 1-cm, ovoid, bright pink, scaling papule (Figure 1). On dermoscopy, the lesion was noted to have a negative network, polymorphous blood vessels, white crystalline structures, and white scale (Figure 2). The biopsy pathology was consistent with a superficial basal cell carcinoma, FeP type (Figure 3). With a histological stain for melanin, the tumor showed focal zones of hypopigmentation at the sites of the tumor's attachment to the epidermis. These hypopigmented zones at the tumor "stalks" alternated with intervening zones of normally pigmented epidermis (Figure 4). The lesion was subsequently destroyed with electrodesiccation and curettage.

\section{Conclusions}

Classically, FeP presents as a pink, light brown, or skincolored papule or plaque on the trunk. Due to nonspecific clinical findings and misdiagnosis, FeP may be more common than previously thought. Clinically, it may resemble benign growths such as dermal nevus, seborrheic keratosis, or soft fibroma [1]. On histology, $\mathrm{FeP}$ has distinct tumor islands with basaloid (often palisading) cells within a fibromatous stroma (Figure 3) [1].

Negative network consists of a relatively light reticulated pattern that mimics a pigmented network, except that the light network surrounds darker areas that fill the spaces between the lines (Figure 2) [2,3]. Negative network has previously been associated with malignant melanoma, acquired and congenital nevi, Spitzoid lesions, and dermatofibromas 


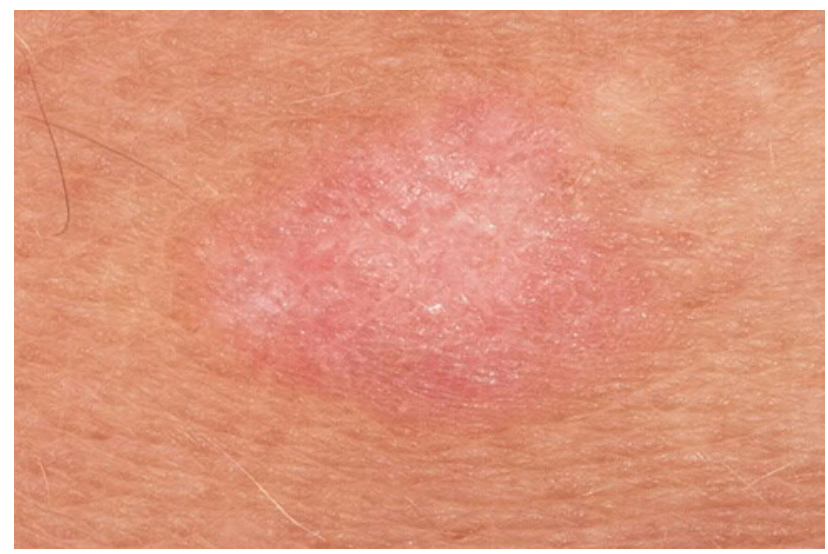

Figure 1. Clinical photograph of FeP. [Copyright: (22019 Yonan et al.]

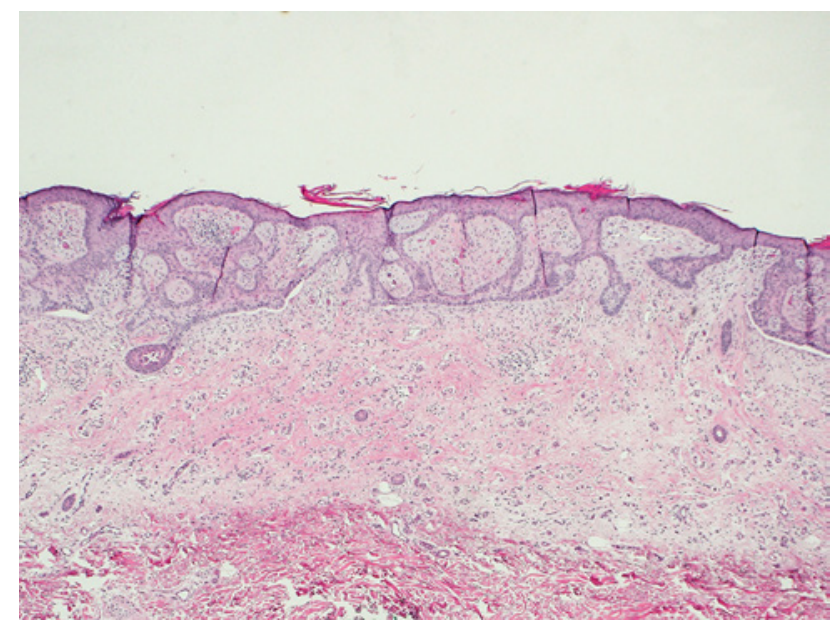

Figure 3. Anastomosing basaloid epithelial strands enclosing round islands of fibrous stroma (hematoxylin and eosin, $\times 40$ ). [Copyright: (C2019 Yonan et al.]

[2]. In our FeP case, the hypopigmented tumor stalks were likely the edges of vertical planes surrounding and enveloping stroma; this created the appearance of a negative network on surface dermoscopy (Figure 4). One prior case report also described the association of $\mathrm{FeP}$ with a negative network that resulted from strands of epithelial cells emerging from the underside of the epidermis [3]. Given the overlapping clinical and dermoscopic features of $\mathrm{FeP}$ with benign and malignant melanocytic and nonmelanocytic tumors, the conservative approach of biopsy is recommended.

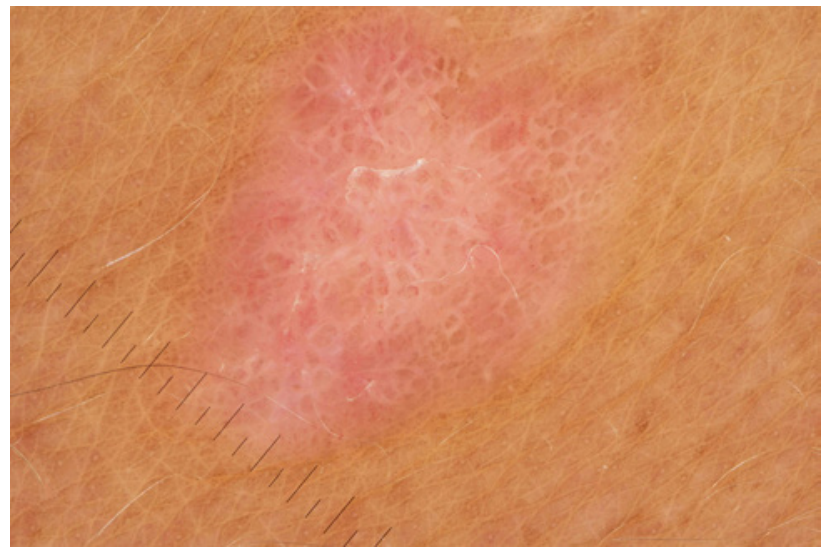

Figure 2. Contact polarized dermoscopic image showing features of negative network, white crystalline structures, polymorphous vessels, and white superficial scale. [Copyright: @2019 Yonan et al.]

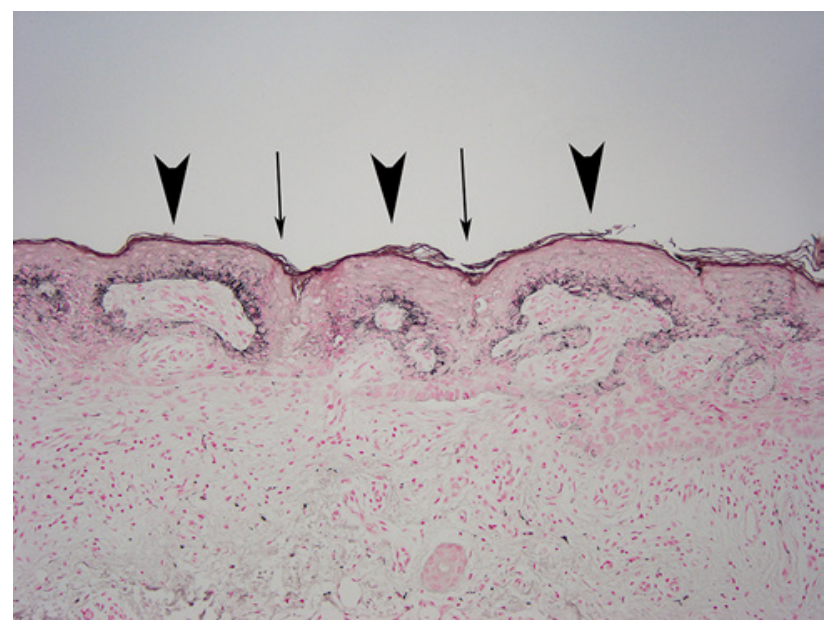

Figure 4. Melanin stain demonstrating hypopigmented tumor stalks (thin arrows) alternating with intervening zones of normally pigmented epidermis (thick arrowheads). The network of hypopigmented tumor stalks creates the appearance of a negative network on dermoscopy (Fontana stain, $\times 100$ ). [Copyright: (O2019 Yonan et al.]

\section{References}

1. Reggiani C, Zalaudek I, Piana S, et al. Fibroepithelioma of Pinkus: case reports and review of the literature. Dermatology. 2013;226(3):207-211.

2. Bassoli S, Ferrari C, Borsari S, et al. Negative pigment network identifies a peculiar melanoma subtype and represents a clue to melanoma diagnosis: a dermoscopic study of 401 melanomas. Acta Derm Venereol. 2013;93(6):650-655.

3. Kornreich DA, Lee JB. White network in fibroepithelioma of Pinkus. JAAD Case Rep. 2016;2(5):400-402. 